\title{
Uma comunidade de espírito e de cultura: a construção do ideário luso-brasileiro na Sociedade de Geografia de Lisboa (1956-1974)
}

\section{A community spirit and culture: the construction of the Luso-Brazilian idea in the Sociedade de Geografia de Lisboa (1956-1974)}

\author{
Tatyana de Amaral Maia \\ Pontifícia Universidade Católica do Rio Grande do Sul \\ tatyana.maia@pucrs.br
}

\begin{abstract}
Resumo: O objetivo deste artigo é analisar a produção e circulação do ideal de comunidade luso-brasileira entre 1956 e 1974. A Sociedade de Geografia de Lisboa reuniu intelectuais portugueses e brasileiros na produção de representações sobre as relações culturais entre Brasil e Portugal, buscando na cultura histórica comum os elementos constitutivos dessa comunidade. A construção de uma identidade supranacional luso-brasileira foi alvo de inúmeros debates intelectuais, sendo utilizada no campo das relações internacionais para promover a aproximação entre Brasil e Portugal. No campo intelectual, esse debate indicava a inadequação de modelos políticos liberais ou comunistas para ambos os países.
\end{abstract}

Palavras-chave: Intelectuais; Relações culturais; Identidade supranacional.

\begin{abstract}
This article is about the production and circulation of the Luso-Brazilian community idea between 1956 and 1974. The Sociedade de Geografia de Lisboa brought together Portuguese and Brazilian intellectuals in the production of representations of cultural relationships between Brazil and Portugal. The construction of a Luso-Brazilian supranational identity has a lot of intellectual debates in the dictatorships period, being used in the field of international relationships to promote the relationships of Brazil and Portugal. Among these intellectuals, the debate had indicated the inadequacy of liberal or communists models for both countries.
\end{abstract}

Keywords: Intellectuals; Cultural policies; Supranational identity. 
Em 1972, durante uma conferência realizada na Comissão de Educação e Cultura da Câmara dos Deputados do Brasil, Adriano Moreira destacava a importância das relações Brasil-Portugal, considerando que ambos os países estavam unidos pelas mesmas condições de espírito e de cultura. ${ }^{1}$ Nesse sentido, integravam um "lar comum", faziam parte de uma única comunidade: a luso-brasileira.

A presença de Adriano Moreira na Câmara dos Deputados do Brasil culmina com uma longa articulação entre os intelectuais dos dois países que se intensificou a partir dos anos 1930. A projeção de uma comunidade luso-brasileira foi obra dessa articulação forjada através de políticas culturais e da criação de espaços de sociabilidade que permitiram a circulação desses homens e de suas ideias. Essa rede integrou intelectuais brasileiros e portugueses vinculados a projetos modernistas conservadores, ${ }^{2}$ atuantes no interior do aparelho estatal e em instituições de pesquisa e cultura entre os anos de 1930 e 1970.

A construção de um ideário luso-brasileiro foi obra de intelectuais brasileiros e portugueses que, ao longo do século $X X$, ingressaram nas fileiras dos dois Estados para promoção de projetos políticos e culturais fortemente amparados no conservadorismo e na defesa dos valores nacionais. O Estado Novo português (1933-1974) implementou políticas culturais sistemáticas dedicadas à produção e circulação de ideias e de intercâmbio de intelectuais entre os dois países. ${ }^{3}$

A atuação dos intelectuais nos governos autoritários, no aparato burocrático ou nos círculos de debates sobre as "questões nacionais" tornou esses atores personagens relevantes na organização e/ou legitimação de projetos políticos nas sociedades contemporâneas. Entre as muitas leituras sobre as relações entre os intelectuais e o poder, destacam-se aquelas dedicadas ao envolvimento dos intelectuais nas disputas políticas e no interior do aparelho estatal. A crença difundida entre a elite intelectual de que seria portadora da "missão" de elevar a consciência da população, de guiar os menos favorecidos e, assim, orientar e planejar os rumos do país mobilizou dezenas de intelectuais, conservadores e revolucionários ao longo dos séculos XIX e XX. Essas leituras ocupam parte significativa da produção historiográfica dedicada ao tema. ${ }^{4}$

No campo do desenvolvimento científico e da expansão cultural, a intervenção do Estado, através da criação de instituições e implementação de políticas sistemáticas para a cultura, está associada à compreensão da importância do campo cultural no direcionamento da sociedade. No caso de regimes

\footnotetext{
1 Em 1972, Adriano Moreira era professor catedrático de Ciências Sociais e Política Ultramarina; Presidente da Sociedade de Geografia de Lisboa; Presidente da Academia Internacional da Cultura Portuguesa e ex-Ministro de Estado do Ultramar. Trata-se de um dos principais defensores do luso-tropicalismo, teoria-síntese elaborada por Gilberto Freyre sobre "o modo português de estar no mundo". A presença de Adriano Moreira na Câmara dos Deputados está integrada às comemorações do sesquicentenário da independência do Brasil e à intensa circulação de intelectuais promovidas pelas diplomacias portuguesa e brasileira desde os anos 1930. Ata da reunião de 15 de junho de 1972 realizada na Câmara dos Deputados do Brasil. Boletim da Sociedade de Geografia de Lisboa, jan./mar., abr./jun., 1974, pp. 35-56, p. 36.

${ }^{2}$ LAFETÁ, João Luiz. 1930: a crítica e o modernismo. 2. ed. São Paulo: Editora 34, 2000; MAIA, Tatyana. Cardeais da cultura nacional: o Conselho Federal de Cultura na ditadura civil-militar (1967-1975). São Paulo: Iluminuras, 2012.

${ }_{3}$ Desde o início do século XX, intelectuais brasileiros e portugueses buscaram aproximar as relações culturais entre Brasil e Portugal. A conferência de Silvio Romero, em 1902, no Real Gabinete Português de Leitura no Rio de Janeiro, é considerada o ponto de partida na construção do ideário da comunidade luso-brasileira. In: RODRIGUES, Jorge Manuel Silva Costa. Da comunidade luso-brasileira à comunidade dos países de língua portuguesa. Dissertação (Mestrado em História) - Universidade Aberta, Lisboa, 1997.

${ }^{4}$ MICELI, Sérgio (Org.). História das Ciências Sociais no Brasil. São Paulo: Revista dos Tribunais, 1989. Intelectuais à brasileira. São Paulo: Companhia das Letras, 2002; __. Intelectuais e Classe dirigente no Brasil (1920-1945). São Paulo: DIFEL, 1979; PECAUT, Daniel. Os intelectuais e a política no Brasil: entre o povo e a nação. Trad. Maria Júlia Golwasser. São Paulo: Ática, 1990. SIRINELLI, Jean-François. Las Élites Culturales. In: RIOUX, JeanPierre e SIRINELLI, Jean-François. Para una Historia Cultural. México: Taurus, 1999. pp. 289-312. ROLLO, Maria Fernanda et al. Ciência, Cultura e Linguagem Portugal no século XX: da Junta de Educação Nacional ao Instituto Camões. Lisboa: Instituto Camões e Imprensa Nacional-Casa da Moeda, 2012; Ó, Jorge Ramos do. Os anos de Ferro: o dispositivo cultural durante a "política do Espírito" (1933-1949). Lisboa: Editorial Estampa, 1999.
} 

autoritários no século XX, observa-se uma dupla dinâmica, marcada de um lado, pelo controle - através de mecanismos de repressão e de censura - e, de outro, por investimentos na produção e divulgação da ciência e da cultura como instrumentos importantes na legitimação dos regimes.

(...) Reconhece-se, portanto, que a cultura envolve uma relação de poder, que pode ser maléfico quando nas mãos de dissidentes, mas benéfico quando circunscrito ao poder autoritário. Percebe-se, pois, a importância de se atuar junto às esferas culturais. Será por isso incentivada a criação de novas instituições, assim como iniciará todo um processo de gestação de uma política de cultura.

No caso português, entre os diversos setores que integravam a política de cultura do Estado, observa-se um conjunto de iniciativas dedicadas à elaboração de narrativas sobre o passado que redefinissem as representações da sociedade portuguesa sobre si e sua participação no mundo, forjando uma nova consciência histórica, integradas às diretrizes políticas implementadas pelo Estado Novo (19331974), sobretudo, em diálogo com a política colonial. Em 1933, o regime criava o Secretariado da Propaganda Nacional do Estado Novo, sob direção de Antônio Ferro (1933-1950), como estratégia institucional de produção de uma "política do espírito" voltada para a defesa dos valores nacionais, elaborando representações sobre a identidade nacional amparadas nas tradições populares e na "missão civilizadora" do Estado português. ${ }^{6}$ O governo de António Salazar iria promover uma série de comemorações, efemérides e exposições dedicadas à produção de uma determinada leitura da trajetória histórica portuguesa e sua identidade nacional associada à defesa do colonialismo tardio. A "Exposição do Mundo Português", em 1940, demonstrava a obra civilizacional portuguesa, com destaque para o caráter pluricontinental do Estado, que ia do "Minho ao Timor", e ressaltava a importância do Brasil nesse sistema de significação. ${ }^{7}$ Contudo, seria após a Segunda Guerra Mundial, com o processo de independência das colônias da África e da Ásia, que o regime salazarista redobraria seus esforços no campo político e diplomático para a manutenção das suas possessões coloniais. Nesse período, o debate sobre a existência de uma cultura luso-brasileira, considerada um exemplo do "modo português de estar no mundo", ampliouse e teve como um de seus desdobramentos a elaboração de uma cultura histórica positiva compartilhada entre Brasil e Portugal. A Sociedade de Geografia de Lisboa tornou-se um espaço de sociabilidade importante na condução desses debates entre intelectuais portugueses e brasileiros, onde se verificam nuances nas representações construídas sobre a identidade supranacional luso-brasileira.

No campo político, a partir do pós-guerra, a noção de luso-tropicalismo elaborada por Gilberto Freyre como uma das faces do "modo português de estar do mundo" foi amplamente difundida em Portugal. O luso-tropicalismo foi apropriado pelo Estado português para qualificar a especificidade de seu processo colonizador e a sua permanência na África. A definição dos elementos constitutivos desse "lar comum" terá no predomínio do contributo cultural português sobre os povos colonizados seu ponto nevrálgico, possibilitando a apropriação pelo regime salazarista dessas representações sobre a presença portuguesa

\footnotetext{
${ }^{5}$ Apesar de Renato Ortiz estar se referindo às relações entre Estado autoritário e políticas culturais no regime militar brasileiro (1964-1985), é possível observar que a dinâmica censura e repressão, de um lado, e o fomento à cultura, de outro, atravessam diversos governos autoritários e ditatoriais no século XX. ORTIZ, Renato. A Moderna Tradição Brasileira. São Paulo: Brasiliense, 1988. p. 116.

${ }^{6}$ A partir de 1944, o SPN passaria a se chamar Secretariado Nacional de Informação, Cultura Popular e Turismo. PINTO, Rui Pedro. Prêmios do Espírito. Um estudo sobre prêmios literários do Secretariado de Propaganda Nacional do Estado Novo. Lisboa: ICS, 2008. p. 55.

${ }^{7}$ CATROGA, Fernando et al. História da História de Portugal - sécs. XIX-XX. Lisboa: Temas \& Debates, 1998. v. 2. p. 269; MATOS, Sérgio Campos. Historiografia e memória social (1945-2000): balanço e perspectivas futuras. In: ARRUDA, José Jobson; FONSECA, Luís Adão da. (Org.). Brasil-Portugal: História, agenda para o milênio. Bauru: EDUSC; São Paulo: FAPESP; Portugal: ICCTI, 2001. pp. 537-558.
} 
no mundo, a partir dos anos 1950 , com especial atenção à teoria do luso-tropicalismo de Gilberto Freyre. ${ }^{8}$ Contudo, ao lado do luso-tropicalismo e a despeito de sua importância, intelectuais portugueses e brasileiros propuseram a existência de uma comunidade luso-brasileira centrada numa cultura histórica compartilhada. A assinatura do Tratado de Amizade e Consulta, em 1953, veio atender às aspirações de medidas políticas mais amplas para afirmação dessa comunidade luso-brasileira, até então mais dinâmicas no campo cultural. O ano de 1974, com o fim do Estado Novo português e o processo de redemocratização irá desmobilizar as políticas culturais de cunho modernista conservador, substituindo-as por projetos de integração com as democracias europeias. ${ }^{9}$

O objetivo deste artigo é analisar a circulação de ideias e a articulação entre intelectuais portugueses e brasileiros no interior da Sociedade de Geografia de Lisboa, entre os anos de 1956 e 1974 , empenhados na produção de narrativas que forjassem o ideal de comunidade luso-brasileira. Esse período foi marcado por uma intensa troca de ideias entre Brasil e Portugal e pela ampla circulação de intelectuais, dinamizando as relações culturais nos dois países a partir da necessidade de fortalecimento do sentimento de identidade supranacional. Serão utilizadas como fontes algumas conferências proferidas na Sociedade e publicadas no Boletim da Sociedade de Geografia de Lisboa dedicadas ao tema.

\section{A Sociedade de Geografia de Lisboa e o Centro de Estudos Brasileiros}

No ano de 1937, foi criado o Centro de Estudos Brasileiros, na Sociedade de Geografia de Lisboa. Seguia-se, a partir de então, uma série de ações do Estado Novo português para a circulação de intelectuais ligados ao Estado Novo brasileiro (1937-1945), com visitas e conferências bilaterais, participação em congressos científicos, efemérides nacionais etc. ${ }^{10}$ A Sociedade de Geografia de Lisboa foi um ambiente cultural importante na circulação das ideias e na formação de uma rede de sociabilidade intelectual dedicada às relações luso-brasileiras. Entre 1937 e 1974, além da criação do Centro de Estudos Brasileiros, há a publicação sistemática de diversos artigos de intelectuais brasileiros e portugueses sobre as dimensões formativas da comunidade luso-brasileira no seu periódico oficial, além das atas dos congressos das "Comunidades Portuguesas no Mundo" publicadas pela instituição.

Os debates em torno da existência de uma comunidade supranacional comum possibilitaram o desenvolvimento de inúmeros conceitos que lançavam luz às características distintas na definição dessa identidade. O elemento comum que os unia era a importância do português e de suas tradições na ocupação e no desenvolvimento de povos no além-mar e distinção de outros processos de colonização. Nas conferências promovidas pelos intelectuais reunidos na Sociedade de Geografia de Lisboa, prevaleciam os aspectos históricos, psicológicos e geográficos, incorporando outros elementos à leitura de

\footnotetext{
${ }^{8} \mathrm{O}$ luso-tropicalismo foi uma doutrina desenvolvida por Gilberto Freyre dedicada às relações culturais estabelecidas pelos portugueses e os povos colonizados. Os primeiros esboços de sua teoria foram apresentados no livro Casa Grande \& Senzala (1933). Nos anos de 1940 e 1950, Freyre fará novas reflexões sobre o tema, especialmente, após as visitas patrocinadas pelo Estado português às colônias do Ultramar, em 1951. Assim, ao lado de Casa Grande \& Senzala, as obras $O$ mundo que o português criou (1940), Um brasileiro em terras portuguesas (1953) e Integração portuguesa nos trópicos (1958); as conferências realizadas em Coimbra "Uma cultura moderna: a luso-tropical" (1951), "Em torno do conceito de tropicalismo" (1952) e "O luso e o trópico" (1961) compunham o conjunto de publicações que consolidavam a teoria-síntese do luso-tropicalismo, amplamente apropriada pelo Estado Novo português na legitimação da sua política colonial, a partir dos anos 1950. Ver: LEME, Rafael Souza Campos de Moraes. Abusos e milagres: um estudo sobre a política externa do luso-tropicalismo (1930-1960). Brasília: Fundação Alexandre Gusmão, 2011 . p. 35.

${ }^{9}$ SANTOS, Luiz Claudio Machado. As relações Portugal-Brasil: do Tratado de Amizade e Consulta ao processo de descolonização lusa na África (1953-1975). Tese (Doutorado em História). Universidade de Brasília, Brasília, 2011.

${ }^{10}$ LEME, Rafael Souza Campos de Moraes. Abusos e milagres: um estudo sobre a política externa do luso-tropicalismo. (1930-1960). Brasília: Fundação Alexandre Gusmão, 2011. p. 48.
} 
Gilberto Freyre que compreendia a mestiçagem como principal característica do mundo luso-tropical. Apropriando-se das análises de Pedro Calmon, Mendes Correa, então presidente da Junta de Investigações do Ultramar e da Sociedade de Geografia de Lisboa, afirmava que o conceito de Calmon ampliava o conceito de luso-tropicalismo de Freyre. Segundo Correa, Calmon propôs o conceito de civilização lusíada ou luso-brasileira para compreender a particularidade da cultura histórica que irmanava Brasil e Portugal. Tal civilização teria se formado a partir do complexo político-militar que envolveu a aventura ultramarina, dos traços da psicologia social do português, gerando uma civilização única, diferenciada das demais civilizações e forjada num meio geográfico próprio, este último marcado pelo clima e relevo dos trópicos. No espírito braudeliano da longa duração, Calmon também recorreu à interdisciplinaridade para compor os quadros sociais e culturais dessa civilização, ainda que mantivesse a hierarquia da ação criadora do homem português no processo civilizacional. Ao fazer referência à conferência de Calmon, Correa traz outros elementos para além da mestiçagem como estruturantes dessa nova civilização:

Não é apenas um resultado biopsíquico de cruzamentos fisiológicos, de hibridez, de mestiçamento, de ausência de prevenções raciais. Não. É mais do que isso, é lato e elevado sentimento de amor fraterno, de universalismo humano, de solidariedade inter-racial, que não se limita a gerar mestiços, mas que difunde e intensifica a alma lírica, uma índole compassiva e generosa (....).

Em 1970, na mesma perspectiva analítica de Correa Mendes, José Beja Neves, vice-presidente da Comissão Luso-brasileira da Sociedade de Geografia de Lisboa, buscava na cultura histórica compartilhada os elementos formativos da comunidade luso-brasileira, relativizando o papel central da mestiçagem na formação sócio-histórica das sociedades forjadas pelos portugueses no ultramar. Os vínculos que favoreciam a construção de uma comunidade comum entre portugueses e brasileiros estavam assentados na língua, na etnia e na cultura, características acionadas constantemente pelo ideário nacionalista desde o final do século XIX. O ideal universalista da civilização, nesse caso, é substituído pelas particularidades nacionais que, transplantadas para os territórios do ultramar, possibilitaram a formação de uma comunidade supranacional fortemente dirigida pelo elemento português. Nessa perspectiva, o passado compartilhado favoreceria a projeção de um futuro para a comunidade luso-brasileira, estimulando as relações internacionais entre ambos os países:

\begin{abstract}
Amplamente produzida, a demonstração de que assim é centrar-nos-ia sobre um passado cuja evocação é sempre as origens de emoções para portugueses e brasileiros; analisando sob todos os ângulos, esse passado deve sobretudo servir como poderosa fonte de inspiração para o futuro. ${ }^{12}$
\end{abstract}

A reconstrução de um passado nacional positivo que enaltecesse 0 Estado português e sua presença nos trópicos teria nas relações culturais Brasil-Portugal seu principal ponto de apoio à elaboração dessa cultura histórica. ${ }^{13} \mathrm{~A}$ memória e a História seriam acionadas e redirecionadas pelo regime salazarista na elaboração de imagens enaltecedoras da obra colonial, com destaque para as características singulares do "modo português de estar no mundo". ${ }^{14}$ Nesse sentido, desde os anos 1930, verifica-se um imenso

\footnotetext{
${ }^{11}$ CORREA, A. A. Mendes. A cultura luso-brasileira. A propósito de duas conferências de Pedro Calmom. Boletim da Sociedade de Geografia de Lisboa. Sociedade de Geografia de Lisboa, out./dez., 1956, pp. 347-357, p. 349.

${ }^{12}$ NEVES, Jose Beja. Projecção futura da comunidade luso-brasileira. Boletim da Sociedade de Geografia de Lisboa. Sociedade de Geografia de Lisboa, jan./set., 1970, pp. 23-34, p. 24.

${ }^{13}$ CASTELO, Cláudia. CASTELO, Cláudia. O modo português de estar no mundo: o luso-tropicalismo e a ideologia colonial portuguesa (1933-1961). Porto: Edições Afrontamento, 1998. p. 35.

14 Expressão cunhada por Adriano Moreira no início dos anos 1950, sendo incorporada pelos círculos intelectuais conservadores e pelo discurso oficial do Estado Novo português. In: CASTELO, Cláudia. Id., p. 13.
} 
trânsito de intelectuais e cientistas brasileiros e portugueses, notadamente aqueles envolvidos em projetos gestados no interior do Estado, atuando na organização de setores como educação e cultura e tecendo redes de aproximação cultural apoiadas pelos governos brasileiro e português (respectivamente, através do Itamaraty e do Ministério dos Negócios Estrangeiros). Contudo, a partir dos anos 1950, o debate sobre o luso-tropicalismo e seus usos políticos é ampliado, em especial, para justificar a permanência das possessões portuguesas em África.

Os Estados-nações modernos incorporaram leituras tradicionais na consolidação da memória e da identidade nacionais, consideradas como instrumentos legítimos na formação de seus cidadãos e na adoção de projetos políticos conservadores. ${ }^{15} \mathrm{~A}$ massificação dos bens culturais e a consolidação da indústria cultural não eliminaram o papel preservacionista do Estado no setor cultural, ao contrário, provocaram a reação dos grupos intelectuais nacionalistas em defesa dos lugares de memória. A associação entre a cultura e a nação, realizada prioritariamente por esses Estados, possibilitou a ingerência do aparelho estatal sobre a identidade nacional. No entanto, essa construção orientada da memória nacional, como afirma Michel Pollak, passa pelo enquadramento das memórias coletivas em favor de determinados interesses que não podem negligenciar os elementos referenciais do grupo social no qual se deseja promover o sentimento de pertencimento. Assim, as memórias nacionais são construídas a partir do enquadramento das memórias coletivas, em geral, apropriando-se da narrativa histórica, da língua e de práticas culturais socialmente valorizadas com o intuito de reforçar o sentimento de pertencimento e difundir as referências simbólicas que precisam ser compartilhadas para validação dos programas elaborados pelos Estados. Para o autor, "todo trabalho de enquadramento de uma memória de grupo tem limites, pois ela não pode ser construída arbitrariamente. Esse trabalho deve satisfazer certas exigências de justificação" ${ }^{16}$

Os intelectuais brasileiros e portugueses ${ }^{17}$ forjaram uma cultura histórica ${ }^{18}$ que favoreceu a legitimidade de projetos políticos fundamentados numa leitura essencialista do passado, através de um sistema de significações sobre as trajetórias nacionais que favoreciam a construção de uma "outra" modernidade, notadamente em defesa de um Estado centralizador e conservador.

Os intelectuais constituíram a categoria social que mais se empenhou no fomento de laços entre o Velho e o Novo Mundo, assim como foram essenciais na elaboração das identidades culturais nacionais e supranacionais. ${ }^{19}$

$\mathrm{Na}$ formação dessa cultura histórica, a experiência colonial brasileira e a formação de uma comunidade luso-brasileira ocupariam um lugar de destaque. Assim, a circulação de intelectuais

\footnotetext{
${ }^{15}$ Sobre a definição do pensamento conservador na modernidade ver: MANNHEIM, Karl. Sociologia. São Paulo: Ática, 1982.

${ }_{17}^{16}$ POLLAK, Michel. Memória, Esquecimento e Silêncio. Estudos Históricos, 1989. v. 2, n. 3, pp. 3-15, p. 9.

17 Entre os intelectuais que defendiam a teoria de uma comunidade luso-brasileira sustentada pela língua, cultura, trajetória histórica compartilhada e integradas estavam: entre os portugueses, por exemplo: Adriano Moreira, Afonso Botelho, Agostinho da Silva, A. Mendes Corrêa, Antônio Quadros, Jorge Dias, Manuel Múrias; entre os brasileiros, por exemplo, Arthur Cézar Ferreira Reis, Gilberto Freyre, Josué Montello, Miguel Reale, Pedro Calmon. O arquivo do Instituto de Alta Cultura, atualmente sob a guarda do Instituto Camões, tem em seus documentos a intensa circulação desses intelectuais e suas ideias em ambos os países, cujo apoio financeiro do Estado português através de políticas sistemáticas de expansão da cultura portuguesa foi constante. Ver pasta: A Expansão da Cultura Portuguesa no Brasil, 18 volumes, Instituto Camões, Lisboa, Portugal.

${ }^{18}$ A cultura histórica pode ser definida como um conjunto de representações sociais elaboradas por historiadores e não historiadores empenhados na produção de narrativas históricas que interferem na consciência histórica dos indivíduos, forjando leituras amplamente difundidas através de diversos suportes culturais e meios de comunicação. Ver: FLORES, Hélio Chaves. Dos feitos e dos ditos: história e cultura histórica. Saeculum. n. 16, jan./jun., 2007, pp. 83-102, p. 95. Disponível em: http://periodicos.ufpb.br/ojs2/index.php/srh/article/view/11374/6488. Acesso em: 06/03/2015.

${ }_{19}$ BEIRED, José Luís Bendicho. Hispanismo e latinismo no debate intelectual ibero-americano. Varia História. v. $30, \mathrm{n}$. 54, set./dez., 2014, pp. 631-654, p. 633 Disponível em: http://www.scielo.br/scielo.php?pid=S0104$87752014000300003 \&$ script=sci_arttext. Acesso em: 10/01/2015.
} 
Uma comunidade de espírito e de cultura: a construção do ideário luso-brasileiro na Sociedade de Geografia de Lisboa (1956-1974) modernistas conservadores integrados às instituições universitárias e de cultura em ambos os países, entre 1930 e 1970, favoreceria a organização e difusão de projetos políticos de modernidades alternativas, de caráter nacionalista e conservador, em contraposição às ideologias alienígenas (liberalismo e comunismo). ${ }^{20}$

A elaboração positiva de uma unidade cultural, uma civilização singular, tal como afirmou Mendes Corrêa $^{21}$, e sua importância nas relações entre os dois países será fortemente apoiada na requalificação do passado compartilhado entre Brasil e Portugal. Afinal, como propôs Theophilo Andrade:

O conceito da comunidade luso-brasileira, que se poderia definir dizendo que ambos os países são dos ramos do cerne anoso, cujas raízes alcançam a ldade Média peninsular (...). Isto é comunidade. O mais é mera aliança, concertada no tempo, de acordo com os interesses políticos. Para aquela exigem-se laços de sangue e origem histórica comum. $^{22}$

A assimetria que marca as representações intelectuais e culturais sobre o tempo na modernidade, onde o passado apresenta possibilidades e experiências que podem ser reformuladas para atender ao horizonte de expectativas, ou seja, aos projetos de sociedade no futuro, são substituídas pela compreensão de que o passado orienta o futuro, num regime de historicidade com pouco espaço para a mudança. Isso é possível, porque

(...) cada maneira de mobilizar a história, corresponderá uma forma de demarcação identitária, bem como esta implicará também a eleição de um padrão de relacionamento cultural projetado. E será a combinação deste puzzle memorial e identitário o complexo responsável pela abertura de algumas portas de relacionamento cultural (e pelo fechamento de outras), pela lembrança de alguns fatos (e pelo esquecimento de outros). Em todos os casos, a leitura e a mobilização da história funciona como elemento central de fundamentação identitária. ${ }^{23}$

Nesse período, diferentemente do século XIX, o "padrão de relacionamento cultural projetado" previa a existência de uma identidade compartilhada, verificada pela existência de elementos estáveis na formação dos dois povos: a língua, o passado, a cultura. A diversidade política e econômica não impedia a existência do ideal unitário desse "lar comum". Ao contrário, à experiência histórica que permitiu a formação de uma identidade cultural comum favoreceria a formação de um bloco de interesses capaz de responder aos desafios colocados pelo futuro.

É certo que brasileiros e portugueses se estimam mutuamente, sentem-se irmãos, ramos de um mesmo tronco, rebentos de uma mesma raiz. É certo, igualmente, que uns no país dos outros se sentem tão bem como se na sua própria pátria estivessem. Ambos os povos têm as mesmas origens étnicas, falam a mesma língua e seguem a mesma religião, e apresentam tão grandes afinidades sentimentais e intelectivas que até o primeiro quartel do século XX tiveram a mesma literatura (...).

\footnotetext{
${ }^{20}$ Para uma discussão detalhada sobre o conceito de modernidades alternativas ver: AARÃO REIS, Daniel. Os processos de modernização e as modernidades alternativas. In: AZEVEDO, Cecília et al. Modernidades Alternativas: Nuestra América e EUA. Rio de Janeiro: FGV, 2009, CD-ROM, pp. 6-11; e, AARÃO REIS, Daniel. Os intelectuais russos e a formulação de modernidades alternativas: um caso paradigmático? Estudos Históricos. n. 37, jan./jun., 2006, pp. 728.

${ }^{21}$ CORREA, A. A. Mendes. Op. cit., p. 347.

22 ANDRADE, Theophilo. Fundamentos históricos da comunidade luso-brasileira. Seminário luso-brasileiro sobre a problemática actual da comunidade lusíada. Sociedade de Geografia de Lisboa, 1973, pp. 177-183, p.178.

${ }^{23}$ PAREDES, Marçal Menezes. Fronteiras culturais e escalas identitárias. A obsessão histórica da alteridade lusobrasileira. Anais do X Encontro Estadual de História. O Brasil no Sul: cruzando fronteiras entre o regional e o nacional, Universidade Federal de Santa Maria, 2010, pp. 1-16, p. 2. http://www.eeh2010.anpuhrs.org.br/conteudo/view?ID_CONTEUDO=558. Acesso em: 1\%/02/2015.
} 
Enfim, pode-se dizer que a amizade dos dois países entra nos domínios das verdades tradicionais ou acromáticas $(. ..){ }^{24}$

É a elaboração de um sistema de significações que busca no passado os elementos condicionantes da cultura, com centralidade para a ação do português, que possibilitava considerar a existência de uma comunidade luso-brasileira, sem preconceito racial, harmonicamente construída pela versatilidade e capacidade de adaptação do homem português nos trópicos, ou seja, uma nova civilização, culturalmente moderna. Dessa forma, a colonização portuguesa distinguia-se das demais experiências coloniais, legitimando a política colonial. Será a partir da história, ou melhor, de uma concepção moderna do tempo histórico, onde o passado (campo de experiências) e o futuro (horizonte de expectativas) ${ }^{25}$ se encontram no presente que intelectuais portugueses e brasileiros modernistas conservadores irão projetar suas leituras sobre a existência da comunidade luso-brasileira, apresentando-a inserida num projeto de modernidade alternativa.

A definição de uma comunidade luso-brasileira que integrasse Brasil, Portugal e, claro, seus domínios no Ultramar, como projeto cultural e político, foi marcada por clivagens intelectuais, apropriações políticas, leituras e ênfases distintas, mobilizando projetos políticos que atendessem às realidades nacionais e aos ambientes culturais específicos. Neste sentido, apesar de acionarem o tripé passado comum, língua e cultura, na identificação dos elementos que concorrem na construção de uma identidade luso-brasileira, os intelectuais e os agentes políticos irão produzir discursos específicos, por vezes, aproximando-se das narrativas oficiais e, em outros momentos, distanciando-se, numa relação de ambivalência, de um pensarduplo. ${ }^{26}$ Esse é o caso dos artigos de Correa e Beja que, para além da força da mestiçagem proposta pelo luso-tropicalismo, elaboram uma cultura histórica centrada no elemento português para compreender a ação civilizadora lusitana.

A defesa de uma cultura transnacional construída dentro das tradições lusas no processo civilizatório de expansão ultramarina foi habilmente utilizada pelo Estado Novo português, a partir dos anos 1950, para justificar a manutenção do colonialismo tardio, substituindo o discurso de superioridade racial que prevaleceu nos anos de 1930 e 1940. No campo intelectual, observa-se, desde os anos 1930, o desenvolvimento de projetos modernistas conservadores orientando uma definição da cultura luso-brasileira a partir de elementos estáveis à sua formação. Tais elementos estão assentados na trajetória histórica compartilhada, nas características psicoculturais do português e na estabilidade e na unidade linguística. Essa definição forneceria a base das identidades nacionais, sendo apropriadas pelo conservadorismo político, observando as diferenças nos diversos contextos e regimes políticos em ambos os países.

O modernismo conservador é uma corrente de pensamento desenvolvida por intelectuais dedicados às relações entre política e cultura, notadamente, à questão da identidade nacional entre os anos de $1930 \mathrm{e}$ 1970 e que atravessou as ciências sociais. ${ }^{27} \mathrm{~A}$ ideia de modernidade, nessa perspectiva, não aparece em oposição à valorização da tradição, ao contrário, os valores fundamentados na tradição são considerados

\footnotetext{
${ }^{24}$ CENTRO DE ESTUDOS BRASILEIROS. Programa. Sua justificação e constituição, seus objetivos. Lisboa: Sociedade de Geografia de Lisboa, 1937. Arquivo da Sociedade de Geografia de Lisboa.

${ }_{25}$ Para compreensão da construção do tempo histórico na modernidade, ver: KOSELLECK, R. Futuro Passado. Barcelona: Paidós, 1993; REIS, José Carlos. História e Teoria. Rio de Janeiro: FGV, 2003.

${ }^{26}$ Os conceitos de ambivalência e pensar-duplo foram propostos por Labourie para compreender o colaboracionismo no regime de Vichy na França. Acredito que ambos os conceitos possam ser apropriados para compreender as relações complexas entre intelectuais e regimes autoritários. In: LABOURRIE, Pierre. 1940-1944: os franceses do pensar-duplo. In: ROLLEMBERG, Denise e QUADRAT, Samantha Vaz. (Orgs.). A construção social dos regimes autoritários: legitimidade, consenso e consentimento no século XX. Rio de Janeiro: Civilização Brasileira, 2010. 3 v., v. 1, pp. $31-44$. 27 LAFETÁ, João Luiz. 1930: a crítica e o modernismo. 2. ed. São Paulo: Editora 34, 2000; MAIA, Tatyana. Cardeais da cultura nacional: o Conselho Federal de Cultura na ditadura civil-militar (1967-1975). São Paulo: lluminuras, 2012.
} 

parte integrante da modernidade. O conceito de tradição, nesse caso, está remetendo tanto à "reabilitação" dos traços de formação originários das sociedades quanto à identificação para superação das mazelas nacionais. No sentido proposto, a tradição traz como marca valorativa a autenticidade dos monumentos, documentos e produções simbólicas eleitos como expressão da nacionalidade. Para esses intelectuais, a cultura só pode ser definida através de uma investigação que contemple o estudo da formação histórica da sociedade. A identidade remeteria à origem de um determinado grupo que supostamente caracterizaria o indivíduo de maneira autêntica.

Em uma abordagem culturalista, a ênfase não é colocada numa herança biológica, (...) mas na herança cultural, ligada à socialização do indivíduo no interior do seu grupo cultural. Entretanto, o resultado é quase o mesmo, pois segundo esta abordagem o indivíduo é levado a interiorizar os modelos culturais que the são impostos, até o ponto de se identificar com o seu grupo de origem. Ainda assim a identidade é preexistente ao indivíduo. Toda identidade cultural é vista como consubstancial com uma cultura particular. ${ }^{28}$

A tese do luso-tropicalismo de Gilberto Freyre e suas apropriações no campo cultural e político ocupam a maior parte da produção historiográfica dedicada às relações entre os intelectuais e o regime salazarista. A construção de uma comunidade luso-brasileira, incluindo neste quadro de representações o luso-tropicalismo de Gilberto Freyre, como "teoria-síntese" das relações de Portugal com os trópicos, será considerada pelos historiadores dedicados ao tema como estruturante das relações culturais Brasil-Portugal no pós-guerra. ${ }^{29}$

Para Cláudia Castelo, é possível perceber a existência de dois momentos de recepção do lusotropicalismo de Gilberto Freyre no campo cultural e político. No período de 1930 a 1940 prevalece em Portugal o conceito de raça como marca do processo civilizacional empreendido pelos portugueses no mundo, ainda que já em diálogo com as características psicossociais do português delineado por Gilberto Freyre, excluindo fundamentalmente o conceito de mestiçagem. A partir dos anos 1950 até o final do governo de Marcelo Caetano (1974), observa-se a intensificação da produção e da circulação de ideias dedicadas à tese do luso-tropicalismo centradas no conceito de cultura e fortemente baseadas na mestiçagem como integração cultural. Se por um lado, certos traços do luso-tropicalismo foram mobilizados pela diplomacia portuguesa e por intelectuais adeptos às análises culturalistas de Freyre, por outro, é certo que as práticas administrativas e a doutrina oficial do regime se mantiveram distantes do ideal lusotropicalista. A incorporação do luso-tropicalismo pelo regime estará associada às mudanças ocorridas na política colonial e na política externa, a partir das pressões dos organismos internacionais e das lutas de independência promovidas pelos povos africanos e asiáticos no pós-guerra. A diplomacia portuguesa irá se apoiar no luso-tropicalismo para justificar a existência de províncias metropolitanas e ultramarinas que faziam parte de uma única unidade político-administrativa, o Estado português. ${ }^{30}$

A emergência da noção de cultura, a partir de meados dos anos 1940, em substituição à noção de raça, trazia consigo a perspectiva de uma comunidade luso-tropical, harmonicamente construída em favor dos povos colonizados, gerando uma civilização socialmente democrática e irmanada nos valores e tradições lusitanas. A "integração cultural" fazia parte da própria trajetória de formação da sociedade portuguesa, uma sociedade nascida da intersecção entre África e Europa. Para Hespanha, nos anos 1970, a escrita de uma narrativa histórica apoiada nas teses de Gilberto Freyre associou o luso-tropicalismo às

\footnotetext{
${ }^{28}$ CUCHE, Denys. A noção de cultura nas ciências sociais. Bauru: EDUSC, 1999. p. 179.

${ }^{29}$ LEME, Rafael Souza Campos de Moraes. Op. cit., p. 35.

30 CASTELO, Cláudia. Op. cit., p. 95.
} 
representações da identidade nacional portuguesa promovida pelo Estado Novo, ou seja, uma "sociedade multicultural, multi-rácica e católica". Essa discussão, tão cara à agenda cultural portuguesa irá variar ao longo do Estado Novo português, conforme as conjunturas nacional e internacional. ${ }^{31}$

\section{Considerações finais}

É possível observar, a despeito da importância do luso-tropicalismo, que as relações culturais Brasil-Portugal ultrapassaram a teoria-síntese de Gilberto Freyre, apesar de incorporá-la, e podem ser compreendidas dentro de um movimento intelectual mais amplo que orientou as políticas culturais entre os dois países, entre os anos de 1930 e 1970. O campo cultural, como um território contestado, marcado por múltiplos interesses e atores que concorrem na construção de representações sobre o mundo social que legitime a opção por determinados modelos de organização societária terá no Estado, no período anteriormente citado, o seu principal financiador e divulgador da produção cultural e científica em ambos os países. No interior da Sociedade de Geografia de Lisboa reuniram-se intelectuais brasileiros e portugueses dedicados à análise de proposição de relações culturais luso-brasileiras apoiadas na cultura histórica compartilhada dos dois Estados-nação, com o predomínio do elemento português e de seus aspectos psicosociais positivos habilmente utilizados no processo de colonização.

Desde o processo de institucionalização do Estado Novo português, observa-se uma preocupação do regime com o protagonismo dos intelectuais nos debates políticos que atravessaram o país desde a Primeira República (1910-1926). Para Rui Pinto, a criação do Secretariado da Propaganda Nacional, dirigido por Antônio Ferro, a Direção Geral dos Serviços de Censura e a Junta da Educação Nacional constituiriam os principais órgãos de controle, negociação e fomento do universo cultural, estabelecendo relações complexas com diversos agentes culturais. Dessa forma, prevaleceria na construção da identidade nacional, tal como elaborada pelo Estado Novo, a ideia de uma "nação plurirracial e pluricontinental", associada a vetores ideológicos de origens diversas. A ideia da "unidade de sentimento e de cultura" amparada na trajetória histórica, pela língua e pela incorporação dos valores superiores lusitanos foi apropriada pelos discursos políticos e ocupou parte importante do cenário cultural dos dois países redefinindo identidades nacionais e supranacionais, apoiada no pensamento conservador. ${ }^{32}$

O conservadorismo presente nestes círculos intelectuais afasta-se do modelo político liberal, considerado embrião da "anarquia política" e cujo maior perigo seria a sua "ameaça potencial à segurança do Estado". No pensamento conservador, a realidade é dotada de normas essenciais que mantêm a ordem e a harmonia social existentes, abalada pelas transformações que desconsideram a formação histórica das sociedades em nome de hipotéticos modelos de desenvolvimento. A valorização da tradição, tão característica no pensamento conservador, busca no passado a essência formadora daquele Estado. ${ }^{33}$

A emergência de projetos políticos e culturais modernos alterou profundamente as relações sociais e de produção ao longo dos séculos XIX e XX. Tais projetos não se desenvolveram como um modelo único e homogêneo e tampouco estão restritos à adoção do modelo liberal surgido em alguns países da Europa Ocidental. O liberalismo foi questionado por diversos setores sociais e, por vezes, abandonado em nome de

\footnotetext{
${ }^{31}$ HESPANHA, Antonio Manuel. As ciências e as problemáticas sociais. In: PERNES, Fernando. Panorama da Cultura Portuguesa no século XX. Porto: Fundação de Serraalves, 2002. v. 1, pp. 327-350, p. 334.

32 PINTO, Rui Pedro. Prêmios do espírito. Um estudo sobre os prêmios literários do Secretariado de Propaganda Nacional do Estado Novo. Lisboa: ICS, 2008. p. 17.

${ }^{33}$ MANNHEIM, Karl. Sociologia. Trad. Emílio Willems, Sylvio Uliana e Cláudio Marcondes, São Paulo: Ática, 1982. p. 127.
} 

projetos nacionais desenvolvidos por governos tanto à direita quanto à esquerda, numa clara tentativa de superar a crise econômica e social produzida pela adoção indiscriminada dos padrões liberais, cujo episódio mais marcante no século XX foi o crash da bolsa de Nova York, em 1929, que arrastou para o abismo diversas economias, corroborando para a crise das frágeis democracias liberais nascidas no pós-Primeira Guerra Mundial. Diversos Estados-nações buscaram modelos de desenvolvimento alheios ao projeto liberal, construindo outras propostas no âmbito das modernidades alternativas. ${ }^{34}$

No Brasil e em Portugal, com a chegada de Getúlio Vargas e António Salazar ao poder, o Estado tornou-se o principal agente no processo de modernização do país. Organizou a burocracia estatal, criando inúmeros órgãos, institutos e agências governamentais cujo desafio era orientar os rumos do desenvolvimento nacional, afastando-se dos padrões liberais e do modelo comunista. Ambos os Estados sustentados pelo ideário nacionalista e pelo papel do Estado como mediador dos conflitos sociais, almejavam superar o atraso e a crise "material e espiritual" que afetavam os dois países no início do século $X X$, mas fortemente ligados a elaboração de leituras sobre o passado nacional que enaltecessem sentimentos de harmonia social e tradições ${ }^{35}$. É nesta atmosfera política e cultural que irá se constituir essa rede de intelectuais modernistas conservadores dedicados à construção e consolidação do ideal de comunidade luso-brasileira.

Tatyana de Amaral Maia: Professora Adjunta do Programa de Pós-Graduação em História da Pontifícia Universidade Católica do Rio Grande do Sul. Pesquisadora colaboradora do Centro de Investigação Transdisciplinar Cultura, Espaço e Memória da Universidade do Porto/Portugal. Pós-Doutorado em História na Universidade do Porto. Doutorado em História no Programa de Pós-Graduação em História na UERJ.

\footnotetext{
${ }^{34}$ AARÃO REIS, Daniel. Op. cit., 2009.

${ }^{35}$ LEME, Rafael Souza Campos. Op. cit., p. 17. 